\title{
Awareness and Attitude Towards COVID-19 Vaccination and Associated Factors in Ethiopia: Cross-Sectional Study
}

\section{Molalegn Mesesle (D)}

School of Midwifery, College of Health Science and Medicine, Wolaita Sodo

University, Wolaita Sodo, Ethiopia
Correspondence: Molalegn Mesesle School of Midwifery, College of Health Science and Medicine, Wolaita Sodo University, Wolaita Sodo, Ethiopia Email emimolaleg@gmail.com
Background: Coronavirus disease (COVID-19) is a deadly virus that continues to afflict many countries worldwide. The development of a COVID-19 vaccine to combat the disease's spread and devastating effects is still ongoing, and as the pandemic progresses, new, more effective vaccines are likely to be created. The aim of this study was to assess awareness and attitude towards COVID-19 vaccination in Ethiopia.

Methods: A population-based cross-sectional e-survey was conducted among 425 participants from March 13, 2021 to April 10, 2021. The survey was conducted using a structured and self-reported questionnaire containing informed consent along with three sections (sociodemographic, awareness, and attitude); a multivariable logistic regression model was performed to determine the variables predicting awareness towards COVID-19 vaccinations.

Results: The mean score of awareness was $4.3(\mathrm{SD}=1.1$ ) out of 7 , with the overall awareness of $40.8 \%$, and the mean score of attitudes was $4.09(\mathrm{SD}=2.16)$ out of 9 , with an overall "positive attitude" score of 24.2\%. College and above educational level (AOR=2.21, 95\% $\mathrm{CI}=1.32,4.62)$, had access to mass media $(\mathrm{AOR}=4.75,95 \% \mathrm{CI}=2.74,8.24)$, and urban residency $(\mathrm{AOR}=2.83,95 \%$ C.I $=1.57,5.09)$ were significantly associated with awareness towards COVID-19 vaccination.

Conclusion: In Ethiopia, there is a poor knowledge toward COVID-19 vaccines, according to the current report. The findings indicate that authorities should implement an urgent health education program and disseminate more reliable information. Using the media, policymakers should take measures to ensure adequate awareness of COVID-19 vaccinations with various stakeholders.

Keywords: attitude, awareness, COVID-19, Ethiopia, vaccination

\section{Introduction}

Coronavirus disease (COVID-19) is a fatal viral disease that continues to afflict many countries around the world. SARS-CoV-2 (severe acute respiratory syndrome coronavirus 2) is a new coronavirus strain that has spread across the world and become a major public health concern. ${ }^{1}$ The COVID-19 epidemic was declared a pandemic by the World Health Organization (WHO) on March 11, 2020. ${ }^{2}$ During this survey, COVID-19 has affected 223 countries, resulting in over 133.978 million reported cases and 2.9 million deaths. ${ }^{3}$

At least seven separate vaccines across three channels have been carried out in countries as of February 18, 2021. Vaccination is prioritized for vulnerable groups in all countries. Simultaneously, more than 200 additional vaccine candidates are 
being developed, with more than 60 of them in clinical trials. COVAX is a component of the ACT Accelerator, which WHO and collaborators launched in 2020. COVAX, the vaccines cornerstone of the ACT Accelerator convened by CEPI, Gavi, and WHO, aims to bring the COVID-19 pandemic's acute phase to an end. ${ }^{4}$

The development of a COVID-19 vaccine to combat the disease's spread and devastating effects is still ongoing, and as the pandemic progresses, new, more effective vaccines are likely to be developed. Vaccine delivery is continuing, and the public acceptance of the COVID-19 vaccine is critical. ${ }^{5,6}$ Given the urgency of mass vaccination against SARS-CoV-2 strategies, vaccine hesitancy is becoming increasingly recognized as a serious public health problem that necessitates extensive research among different population groups to fully understand its triggers and prevalence. ${ }^{7,8}$

Ethiopian authorities decided to use the COVID-19 vaccine from Astra Zeneca via the COVAX Facility. Ethiopia received 2.184 million doses of COVID-19 vaccines on March 7, 2021. Ethiopian Airlines delivered Astra Zeneca vaccines approved and manufactured by Serum Institute of India (SII) at Bole International Airport. ${ }^{9}$ The Ethiopian Ministry of Health introduced the COVID-19 vaccine at a high-level national event held at Eka Kotebe COVID-19 Hospital on March 13, 2021, where front-line health workers were vaccinated to mark the start of the vaccination campaign. $^{10}$

However, there is a lot of debate about COVID-19 vaccinations among Ethiopians in general. A large percentage of Ethiopians are hesitant to get the COVID-19 vaccine. According to a global survey of potential COVID-19 vaccine approval, $48 \%$ of the study populations are uncertain about the COVID-19 vaccines and whether or not they would get the vaccine. ${ }^{11}$ Similarly, a Chinese study discovered that only slightly more than half of their population $(54 \%)$ planned to get vaccinated. ${ }^{12}$ While the most important measure of contribution to the spread of the virus is to prevent oneself from being exposed to COVID-19, it is therefore vital to vaccinate the most vulnerable group of people as soon as possible. ${ }^{13}$ There is no research on COVID-19 vaccination awareness and attitudes in Ethiopia. As a result, the aim of this study was to assess awareness and attitude towards COVID-19 vaccination in Ethiopia.

\section{Methods}

A population-based cross-sectional explanatory e-survey was conducted in Ethiopia. The survey took place from
March 13, 2021 to April 10, 2021, coinciding with the start of COVID-19 vaccination campaign in Ethiopia. This research used a Google Form to collect data from respondents about their awareness and attitude towards COVID19 vaccination. During data collection, a shared connection was created and disseminated publicly on various social media platforms (Facebook, Telegram, and Email).

The author shared the link to the questionnaire on the social media sites listed above, and in order to comply with the website's terms and conditions regarding the responses of respondents, the following question was added at the end of the questionnaire on Google Forms: "By submitting this form, do you consent to the Term and Conditions of Google Forms?" and if they agreed with this Term and Conditions of Google Forms their responses can be submitted.

As a result, I am assured that my data collection process complied with the Google Forms website's Terms and Conditions. The survey was advertised with online contact mode and only volunteers were included without intensive. The response rate was enhanced by recommunicating with participants and multiple entries from the same individual was prevented by giving code to each participant. The questionnaire included closed-ended questions about the respondents' socio-demographics characteristics and awareness towards COVID-19 vaccine. The inclusion criteria of participant were (a) being an Ethiopian, (b) having voluntary to participate, (c) age greater than or equal to 18 , (d) user of the social media, and (e) can read and understand the national language Amharic. The study was conducted following the Checklist for Reporting Result of Internet ESurveys guidelines. $^{14}$

Since there has been no prior research on awareness and attitude toward COVID-19 vaccine in Ethiopia, I decided that the best assumption (P) would be $50 \%$. Sample size was estimated using the single population proportion formula with the following factors in mind: marginal error of $0.05,95 \%$ confidence interval, and p-value 0.5 . For this analysis, assume a $10 \%$ nonresponse rate. The final sample size of 425 participants was estimated.

\section{Measurement}

Awareness towards COVID-19 vaccine was measured based on survey tool and guidance. ${ }^{15}$ The questioner about awareness had 7 items as presented in Table 1 with a category ("Yes", "No"). The awareness level was assessed by 
Table I Awareness of Respondents Towards COVID-19 Vaccine in Ethiopia, 2021 ( $n=425)$

\begin{tabular}{|c|c|c|}
\hline Variables & Frequency & $\begin{array}{l}\text { Percent } \\
\text { (\%) }\end{array}$ \\
\hline \multicolumn{3}{|l|}{$\begin{array}{l}\text { Do you heard about the COVID-I9 } \\
\text { vaccine? }\end{array}$} \\
\hline Yes & 295 & $46.3 \%$ \\
\hline No & 130 & $53.7 \%$ \\
\hline \multicolumn{3}{|l|}{ Is COVID-I9 vaccine effectiveness? } \\
\hline Yes & 71 & $16.7 \%$ \\
\hline No & 354 & $83.3 \%$ \\
\hline \multicolumn{3}{|l|}{$\begin{array}{l}\text { Currently there is effective cure for } \\
\text { COVID-2019 }\end{array}$} \\
\hline Yes & 373 & $12.2 \%$ \\
\hline No & 52 & $87.8 \%$ \\
\hline \multicolumn{3}{|l|}{$\begin{array}{l}\text { Currently there is effective vaccine } \\
\text { to protect against COVID-19 }\end{array}$} \\
\hline Yes & 340 & $80 \%$ \\
\hline No & 52 & $20 \%$ \\
\hline \multicolumn{3}{|l|}{$\begin{array}{l}\text { COVID- } 19 \text { vaccine started in } \\
\text { Ethiopian }\end{array}$} \\
\hline Yes & 318 & $74.8 \%$ \\
\hline No & 107 & $25.2 \%$ \\
\hline \multicolumn{3}{|l|}{$\begin{array}{l}\text { The newly discovered COVID-19 } \\
\text { vaccine differ from other vaccine }\end{array}$} \\
\hline Yes & 173 & $40.7 \%$ \\
\hline No & 252 & $59.3 \%$ \\
\hline \multicolumn{3}{|l|}{$\begin{array}{l}\text { Even if there is a vaccine other } \\
\text { preventive measures are very } \\
\text { important }\end{array}$} \\
\hline Yes & 262 & $38.4 \%$ \\
\hline No & 163 & $61.6 \%$ \\
\hline
\end{tabular}

assigning 1 point for each correct answer and the knowledge level indicated by two categories: Poor for (of $7<5$ items) and good for (of $7>4$ items). Q1: Do you heard about the COVID-19 vaccine?, Q2: Is COVID-19 vaccine effective?, Q3: Currently there is no effective cure for COVID-2019, Q4: Currently there is an effective vaccine to protect against COVID-19?, Q5: COVID-19 vaccine started in Ethiopian?, Q6: The newly discovered COVID-19 differ from other vaccine?, and Q7: Even if there is a vaccine other preventive measures are very important?

The attitude level was also assessed by assigning one point for each correct answer and the attitude level indicated by two categories ("agree", "disagree"). Negative attitude (of $9<6$ items) and positive attitude ( $\geq 6$ of 9 item). Q1: Is the newly discovered COVID-19 vaccine is safe? Q2: Is the COVID-19 is essential for us, Q3: will you take the COVID-19 vaccine? Q4: Is the vaccine the only solution for COVID-19? Q5: Is the COVID-19 vaccine should be distributed fairly? Q6: Is important to get the vaccine? Q7: worry about unforeseen impact? Q8: Preferred natural immunity rather than vaccine? and Q9: will make the vaccine available for all citizens for free? The awareness and attitude question adopted from different studies. ${ }^{16,17}$

The data was coded, washed, recoded, and entered into epi-data version 3.1 before being transferred to SPSS window version 21 for analysis. To present the data, a table, graph, and a statement were used. Bivariate logistic regression analysis was used to investigate the relationship between independent and dependent variables. All variables in the bivariate logistic regression model with a p-value less than 0.25 were entered into the multivariable logistic regression model to control for potential confounding, and variables in the multiple logistic regression model with a p-value less than or equal to 0.05 were considered statistically significant.

\section{Result}

\section{Socio-Demographic Characteristics}

A total of 425 participants in this study were included. The average age of participants was 29.2 years $(\mathrm{SD}=9.8)$. Approximately half were male $216(50.8 \%)$ and 195 $(45.8 \%)$ had college and above followed by secondary school 180 (42.4\%). Most were single/divorced/widowed 309 (72.5\%) (Table 2).

\section{Awareness Towards COVID-19 Vaccine}

The mean score of awareness was $4.3(\mathrm{SD}=1.1)$ out of 7 , with the overall awareness of $40.8 \%$. The mean score of awareness was significantly high among participants who reported having college and above level of education, have mass media, and urban residency. Less than half of respondents $46.3 \%$ heard about COVID-19 vaccination, $83.3 \%$ of participants know that currently there is no effective cure for COVID-19, and $80 \%$ know that as there is an effective vaccine for COVID-19 (Table 1).

\section{Attitude Towards COVID-19 Vaccine}

The distribution of each of the attitude items towards the COVID-19 vaccine is presented in Figure 1. The mean score of attitudes was $4.09(\mathrm{SD}=2.16)$ out of 9 , with an overall "positive attitude" score of $24.2 \%$. From 
Table 2 Socio-Demographic Characteristics of Respondents in Ethiopia, 2021 ( $n=425)$

\begin{tabular}{|c|c|c|}
\hline Variables & Frequency & Percent (\%) \\
\hline \multicolumn{3}{|l|}{ Age } \\
\hline $18-29$ & 223 & $52.5 \%$ \\
\hline $30-49$ & 185 & $43.5 \%$ \\
\hline$>49$ & 17 & $4.0 \%$ \\
\hline \multicolumn{3}{|l|}{ Sex } \\
\hline Male & 216 & $50.8 \%$ \\
\hline Female & 209 & $49.2 \%$ \\
\hline \multicolumn{3}{|l|}{ Religion } \\
\hline Orthodox & 148 & $34.7 \%$ \\
\hline Muslim & 70 & $16.4 \%$ \\
\hline Protestant & 202 & $47.4 \%$ \\
\hline Catholic & 5 & $1.2 \%$ \\
\hline \multicolumn{3}{|l|}{ Occupation } \\
\hline Merchant & 44 & $10.3 \%$ \\
\hline Government employee & 155 & $36.4 \%$ \\
\hline Daily laborer & 79 & $18.5 \%$ \\
\hline Students & 132 & $31.0 \%$ \\
\hline \multicolumn{3}{|l|}{ Educational status } \\
\hline Primary education & 50 & $11.7 \%$ \\
\hline Secondary education & 180 & $42.3 \%$ \\
\hline Collage and above & 195 & $45.8 \%$ \\
\hline \multicolumn{3}{|l|}{ Mass media } \\
\hline Yes & 277 & $65 \%$ \\
\hline No & 148 & $35 \%$ \\
\hline \multicolumn{3}{|l|}{ Residence } \\
\hline Urban & 358 & $84 \%$ \\
\hline Rural & 67 & $16 \%$ \\
\hline
\end{tabular}

participants, $40.7 \%$ of participants agreed that the newly discovered COVID-19 vaccine is safe, only $30 \%$ of respondents agreed on the COVID-19 vaccination is essential, and $56.9 \%$ of respondents agreed that the vaccine will be fairly distributed (Figure 1).

\section{Factors Associated with Participants' Awareness Towards COVID-19 Vaccine}

After adjusting for the potential confounding, multivariable logistic regression analysis with backward conditional method indicated that educational level, place of residence, and communication media (mass media) were significantly associated with awareness towards COVID-19 vaccine. Educational level was one that was significantly associated with the level of awareness towards COVID-19 vaccination. Participants who have college and above the educational level were 2.21 time $(\mathrm{AOR}=2.21,95 \%$ $\mathrm{CI}=1.32$, 4.62) more likely to have awareness towards COVID-19 vaccination as compared with participants who have primary educational level. Odds of awareness towards COVID-19 vaccine were higher among participants who had access to mass media. Participants who have mass media have 4.75 time $(\mathrm{AOR}=4.75,95 \% \mathrm{CI}$ $=2.74,8.24$ ) more likely to have knowledge about COVID-19 vaccine than when compared with participants have no access to mass media. Residency was another factor that affects awareness about COVID-19 vaccine. Among participants who live in the urban area, there were more than two-folds $(\mathrm{AOR}=2.83,95 \% \mathrm{C} . \mathrm{I}=1.57$, $5.09)$ to have more awareness than participants who live in rural area (Table 3).

\section{Discussion}

Vaccination is credited with eradicating smallpox and controlling infectious diseases in many parts of the world (for example, rubella, diphtheria, polio). As a result, scientists have been working feverishly to develop and test new vaccines to defend against SARS-CoV-2, with unprecedented scientific progress on COVID-19. ${ }^{18}$

The COVID-19 vaccine has been framed as the perfect solution for halting the current pandemic. A large number of vaccine candidates are being developed, and several clinical trials with promising results have recently been published, leading to a number of countries authorizing specific vaccines for use in vaccination programs in Ethiopia, the government has already started the COVID19 vaccination for risky groups. ${ }^{10}$ Despite the fact that Ethiopia has several vaccination programs, the complete newness of the COVID-19 vaccination roll-out raises concerns regarding vaccine knowledge, attitude, delivery, and acceptance. It also raises concerns about the general public's awareness of the COVID-19 vaccine and vaccination. The findings of a novel study conducted in Ethiopia to determine awareness toward the COVID-19 vaccine and related factors are presented in this paper. The results of this study will be critical in the development of a COVID19 vaccine knowledge and health education program.

COVID-19 vaccination awareness was poor (40.8\%) in the current report, compared to $78 \%$ in a study conducted in Bangladesh. ${ }^{16}$ COVID-19 vaccine awareness was found to be affected by educational level, communication media (mass media), and place of residence in this study. Awareness regarding COVID-19 vaccine was not significant in terms of participant's sex and age. The result from 


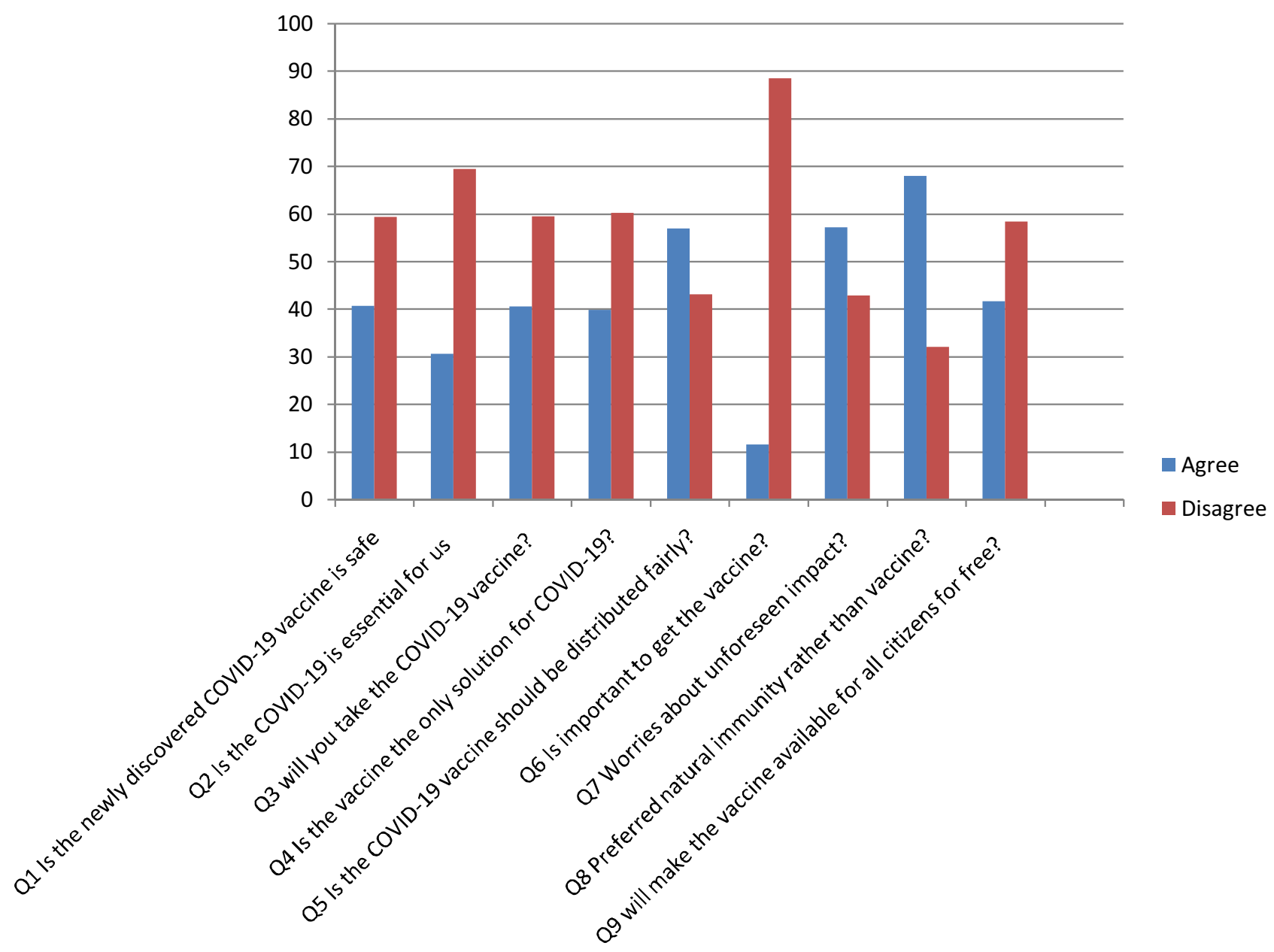

Figure I Attitude towards COVID-19 vaccine in Ethiopia, 202 I $(n=425)$.

of current study was similar to a study done in Bangladesh. ${ }^{16}$

One of the important associated factors with awareness of the COVID-19 vaccine is educational level. Participants with educational level college and above have a better understanding of the COVID-19 vaccine than those with a primary education. The current study's findings in line with those of a study conducted in Syria and Bangladesh. ${ }^{16,19}$ The possible reason might be that those with a high level of education (a diploma or higher) have more access to information, and comprehension abilities will help them to know and react towards COVID-19 vaccine.

Another aspect that was associated with COVID-19 vaccine awareness was the presence of mass media. Participants who have access to the media are 1.6 times more likely to be aware of the COVID-19 vaccine than those who do not. The current study's finding is similar with those of a study conducted in Sheka, Ethiopia. ${ }^{20}$
The COVID-19 vaccine was launched by the Ethiopian Ministry of Health at a high-level national event held at Eka Kotebe COVID-19 Hospital on March 13, 2021. The event was broadcast live on various television outlets, and the COVID-19 vaccination was also advertised in the media. Vaccination information is available to those who have access to the media. ${ }^{10}$ The location of one's residence is also a significant factor in COVID-19 vaccination knowledge. Respondents who live in an urban environment are more than twice as likely to be aware about COVID-19 vaccination as those who do not live in an urban setting. Research conducted in Bangladesh supports the findings of this study. ${ }^{16}$

\section{Conclusion}

The COVID-19 pandemic continues to wreak havoc on lives and livelihoods around the world, but the COVID-19 vaccine offers a ray of hope for the future. In Ethiopia, there is a poor knowledge toward COVID-19 vaccines, 
Table 3 Factors Associated with Awareness Towards COVID-19 Vaccine in Ethiopia, 202I ( $n=425)$

\begin{tabular}{|c|c|c|c|c|}
\hline Variables & Frequency & Percent (\%) & $\begin{array}{l}\text { Crude OR } \\
\text { With } 95 \% \text { C.I }\end{array}$ & $\begin{array}{l}\text { Adjusted OR } \\
\text { With } 95 \% \text { C.I }\end{array}$ \\
\hline \multicolumn{5}{|l|}{ Sex } \\
\hline Male & 216 & $50.8 \%$ & $2.26(1.5,3.38)$ & $1.05(0.63,1.76)$ \\
\hline Female & 209 & $49.2 \%$ & I & 1 \\
\hline \multicolumn{5}{|l|}{ Educational status } \\
\hline Primary education & 50 & $11.7 \%$ & I & I \\
\hline Secondary education & 180 & $42.3 \%$ & $1.63(0.84,3.14)$ & I.36(0.67, 2.75) \\
\hline Collage and above & 195 & $45.8 \%$ & $2.65(1.4,4.99)$ & $2.21(1.32,4.62)^{*}$ \\
\hline \multicolumn{5}{|l|}{ Mass media } \\
\hline Yes & 277 & $65 \%$ & $4.09(2.69,6.22)$ & $4.7(2.74,8.24)^{*}$ \\
\hline No & 148 & $35 \%$ & 1 & 1 \\
\hline \multicolumn{5}{|l|}{ Residence } \\
\hline Urban & 358 & $84 \%$ & $2.15(1.27,3.63)$ & $2.8(1.57,5.09)^{*}$ \\
\hline Rural & 67 & $16 \%$ & I & 1 \\
\hline
\end{tabular}

Note: *Significant association at $\mathrm{P}$-value $<0.05$.

according to the current report. The findings indicate that authorities should implement an urgent health education program and disseminate more reliable information. Using the media, policymakers and various stakeholders should take measures to ensure adequate knowledge towards COVID-19 vaccinations through the community.

\section{Ethical Consideration}

Ethical clearance was obtained from Wolaita Sodo University College of Health Science and Medicine Ethical Review Board with reference number CHSM/ ERC/38. Online informed consent was obtained from participants, and this study was conducted in accordance with the declaration of Helsinki. Anonymity and confidentiality were ensured.

\section{Acknowledgment}

I would like to express my heartfelt thanks to Wolaita Sodo University and all individuals for their contribution and cooperation.

\section{Funding}

This study did not obtain any particular funding from government, commercial, or non-profit funding agencies.

\section{Disclosure}

The author declares that there is no conflict of interest.

\section{References}

1. Pal M, Berhanu G, Desalegn C, et al. Severe acute respiratory syndrome coronavirus-2 (SARS-CoV-2): an update. Cureus. 2020;12(3). doi:10.7759/cureus.7423

2. Cucinotta D, Vanelli M. WHO declares COVID-19 a pandemic. Acta bio-medica Atenei Parm. 2020;91:157. doi:10.23750/abm.v91i1.9397

3. World Health Organization. WHO coronavirus disease (COVID-19) dashboard. 2021 [cited 10 April 2021]. Available from: https:// covid19.who.int/table. Accessed June 3, 2021.

4. World Health Organization. Statement of the WHO global advisory committee on vaccine safety (GACVS) COVID-19 subcommittee on safety signals related to the AstraZeneca COVID-19 vaccine. 2021.

5. Wibawa T. COVID-19 vaccine research and development: ethical issues. Trop Med Int Heal. 2021;26:14-19. doi:10.1111/tmi.13503

6. Reiter PL, Pennell ML, Katz ML. Acceptability of a COVID-19 vaccine among adults in the United States: how many people would get vaccinated? Vaccine. 2020;38:6500-6507. doi:10.1016/j. vaccine.2020.08.043

7. Strategic Advisory Group of Experts on Immunization (SAGE). Vaccine hesitancy survey questions related to SAGE vaccine hesitancy matrix. https://www.who.int/immunization/programmes_sys tems/Survey_Questions_Hesitancy.pdf. Accessed March 14, 2021.

8. Butler R, MacDonald NE, Eskola J, et al. Diagnosing the determinants of vaccine hesitancy in specific subgroups: the Guide to Tailoring Immunization Programmes (TIP). Vaccine. 2015;33 (34):4176-4179. doi:10.1016/j.vaccine.2015.04.038

9. World Health Organization. 2.2 million COVID-19 vaccines allocated by the COVAX Facility arrive in Ethiopia, marking the start of the country's COVID-19 vaccination campaign. 2021.

10. World Health Organization. Ethiopia introduces COVID-19 vaccine in a national launching ceremony. 2021.

11. Lazarus JV, Ratzan S, Palayew A, et al. Hesitant or not? A global survey of potential acceptance of a COVID-19 vaccine. medRxiv. 2020. doi: $10.1101 / 2020.08 .23 .20180307$

12. Lin Y, Hu Z, Zhao Q, Alias H, Danaee M, Wong LP. Understanding COVID-19 vaccine demand and hesitancy: a nationwide online survey in China. PLoS Negl Trop Dis. 2020;14:e0008961. doi:10.1371/ journal.pntd.0008961 
13. Xiao Y, Torok ME. Taking the right measures to control COVID-19. Lancet Infect Dis. 2020;20:523-524. doi:10.1016/S1473-3099(20) 30152-3

14. Eysenbach G. Improving the quality of web surveys: the checklist for reporting results of internet E-surveys (CHERRIES). $J$ Med Internet Res. 2004;6:e34. doi:10.2196/jmir.6.3.e34

15. World Health Organization. Survey tool and guidance: rapid, simple, flexible behavioural insights on COVID-19. 2020.

16. Islam MS, Siddique AB, Akter R, et al. Knowledge, attitudes and perceptions towards COVID-19 vaccinations: a cross-sectional community survey in Bangladesh. medRxiv. 2021.

17. Kazi Abdul M, Khandaker Mursheda F. Knowledge, attitude and acceptance of a COVID-19 vaccine: a global cross-sectional study. 2020 .
18. Mcateer J, Yildirim I, Chahroudi A. The vaccines act: deciphering vaccine hesitancy in the time of COVID-19. Clin Infect Dis. 2020;71:703-705. doi:10.1093/cid/ciaa433

19. Labban L, Thallaj N, Labban A. Assessing the level of awareness and knowledge of COVID 19 pandemic among Syrians. Arch Med. 2020;12:8. doi:10.36648/1989-5216.12.3.309

20. Gelaw AB, Andargie SA. Assessment on awareness towards preventive measures of COVID-19 in Sheka, South Nation Nationalities and Peoples of Region, Southwestern Ethiopia: community based cross-sectional study. 2020.

\section{Publish your work in this journal}

Infection and Drug Resistance is an international, peer-reviewed openaccess journal that focuses on the optimal treatment of infection (bacterial, fungal and viral) and the development and institution of preventive strategies to minimize the development and spread of resistance. The journal is specifically concerned with the epidemiology of antibiotic resistance and the mechanisms of resistance development and diffusion in both hospitals and the community. The manuscript management system is completely online and includes a very quick and fair peerreview system, which is all easy to use. Visit http://www.dovepress.com/ testimonials.php to read real quotes from published authors. 